\title{
DÜBLIN
}

Technological University Dublin

ARROW@TU Dublin

Articles

School of Chemical and Pharmaceutical

Sciences

2016-5

\section{A Model for the Voltammetric Behaviour of TiO2 Memristors}

John Cassidy

Technological University Dublin, john.cassidy@tudublin.ie

Daryl Fox

Technological University Dublin

Tony Betts

Technological University Dublin, anthony.betts@tudublin.ie

Follow this and additional works at: https://arrow.tudublin.ie/scschcpsart

Part of the Chemicals and Drugs Commons, and the Pharmacy and Pharmaceutical Sciences Commons

\section{Recommended Citation}

Cassidy, J., Fox, D. \& Betts, A. (2016) A Model for the Voltammetric Behaviour of TiO2 Memristors, Journal of Solid State Electrochemistry, 20(5), 1229-1234 DOI : 10.1007/s10008-015-3109-z

This Article is brought to you for free and open access by the School of Chemical and Pharmaceutical Sciences at ARROW@TU Dublin. It has been accepted for inclusion in Articles by an authorized administrator of ARROW@TU Dublin. For more information, please contact arrow.admin@tudublin.ie, aisling.coyne@tudublin.ie, gerard.connolly@tudublin.ie.

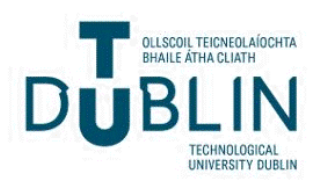




\section{A model for the voltammetric behaviour of $\mathrm{TiO}_{2}$ memristors}

\section{John F. Cassidy, Daryl Fox \& Anthony J. Betts}

\section{Journal of Solid State}

\section{Electrochemistry}

Current Research and Development in Science and Technology

ISSN 1432-8488

Volume 20

Number 5

J Solid State Electrochem (2016) 20:1229-1234

DOI 10.1007/s10008-015-3109-z

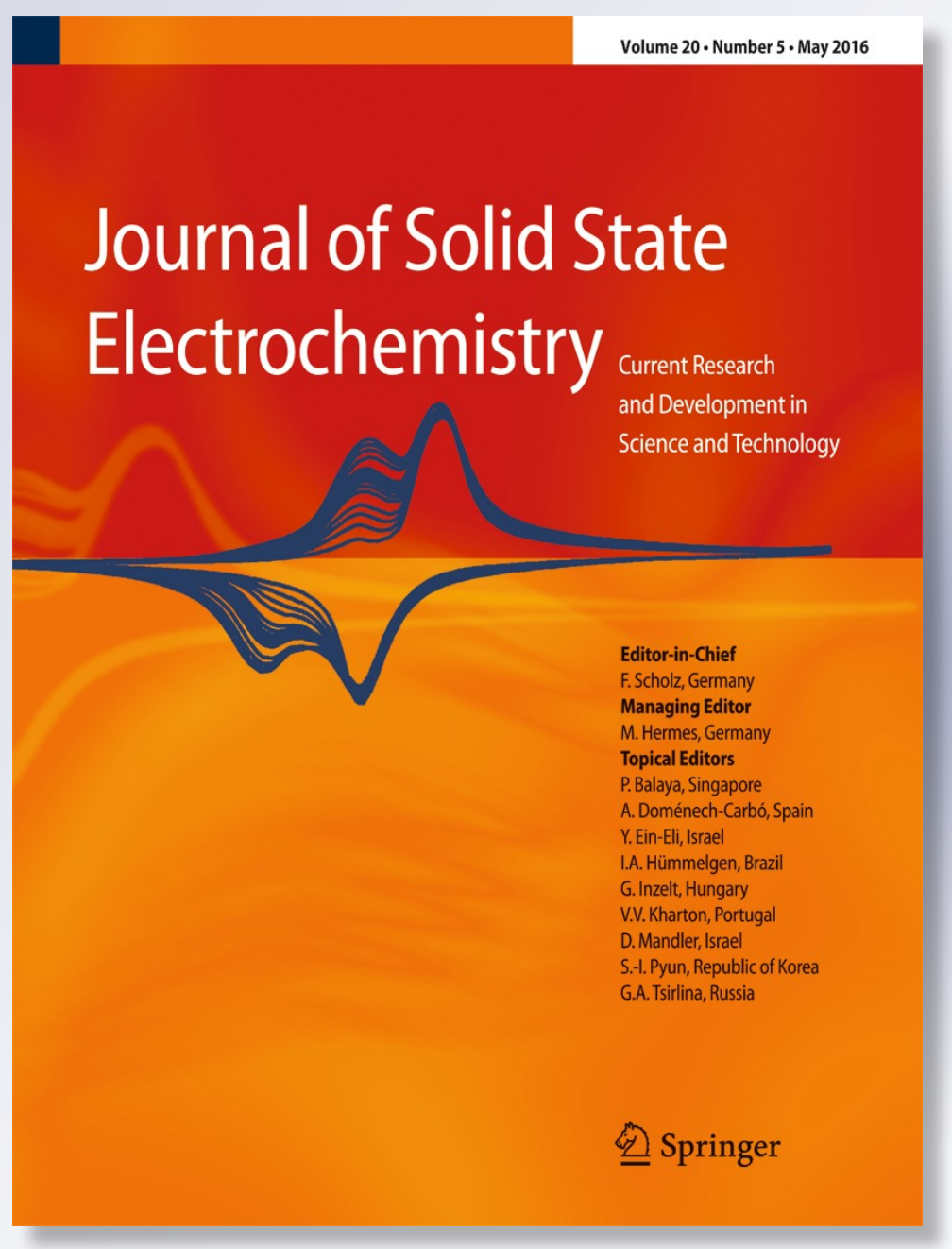

Springer 
Your article is protected by copyright and all rights are held exclusively by SpringerVerlag Berlin Heidelberg. This e-offprint is for personal use only and shall not be selfarchived in electronic repositories. If you wish to self-archive your article, please use the accepted manuscript version for posting on your own website. You may further deposit the accepted manuscript version in any repository, provided it is only made publicly available 12 months after official publication or later and provided acknowledgement is given to the original source of publication and a link is inserted to the published article on Springer's website. The link must be accompanied by the following text: "The final publication is available at link.springer.com". 


\title{
A model for the voltammetric behaviour of $\mathrm{TiO}_{2}$ memristors
}

\author{
John F. Cassidy ${ }^{1} \cdot$ Daryl Fox $^{2} \cdot$ Anthony J. Betts $^{2}$
}

Received: 12 October 2015 /Revised: 17 December 2015 / Accepted: 21 December 2015 / Published online: 12 January 2016

(C) Springer-Verlag Berlin Heidelberg 2016

\begin{abstract}
A model is solved based on the Nernst Planck equation to calculate the diffusion and migration currents for a species in a thin layer (about $200 \mathrm{~nm}$ ) confined between two electrodes. This is proposed to account for the current voltage behaviour of a memristor constructed in a similar fashion. At the working electrode, an electroactive species is oxidised and at the counter electrode, the same species is reduced. Upon application of a simple voltammetric waveform, the migration current exhibits a resistance profile at slow scan rates and hysteresis at faster scan rates, indicative of memristor behaviour.
\end{abstract}

Keywords Nernst Planck equation · Memristor · Digital simulation $\cdot$ Titanium dioxide

\section{Introduction}

A memristor is a passive device that has a resistance whose magnitude depends on the amount of charge which has passed through it. Typically, it takes the form of a very thin (tens of $\mathrm{nm}$ ) layer of $\mathrm{TiO}_{2}$ sandwiched between two electrodes which can be $\mathrm{Pt}, \mathrm{Al}$ or $\mathrm{Au}$. While there have been many examples of memristors [1], based on a variety of systems [2], there has not been a great deal of work understanding how the charge is

John F. Cassidy

john.cassidy@dit.ie

1 School of Chemical and Pharmaceutical Sciences, Dublin Institute of Technology, Kevin Street Lower, Dublin D08 NF82, Ireland

2 Applied Electrochemistry Group, Dublin Institute of Technology, Kevin Street, Dublin D08 NF82, Ireland passed through the device. In the paper by Strukov et al. [3], there is a diagram of a $\mathrm{TiO}_{2}$ layer which shows an image of a memristor which is converted from an undoped (highresistance) form to a doped (low-resistance) form by means of a passage of charge. This is a two-state system where the high-resistance region is gradually taken over by a lowresistance region as the $\mathrm{Ti}^{4+}$ is gradually reduced, yielding oxygen vacancies that are the charge carriers. This model does yield the Lissajous current-voltage profile observed experimentally [3].

The doping takes the form of reduction of $\mathrm{TiO}_{2}$ and the movement of oxygen vacancies, taken to be positive species [3]. However, there is an issue with this transformation. If the $\mathrm{TiO}_{2}$ is getting reduced at one side of the component, then there should be an equal amount of oxidation on the opposite electrode of the component. This issue has not been taken into account in many publications. For example, the following equation could represent the reduction process $[4,5]$.

$2 \mathrm{TiO}_{2}+\mathrm{H}_{2} \mathrm{O}+2 \mathrm{e}^{-} \rightarrow \mathrm{Ti}_{2} \mathrm{O}_{3}+2 \mathrm{OH}^{-}$

The presence of the reduced Ti may be seen spectroscopically as it is blue in colour [6,7]. The question remains whether this can readily occur in the solid state, and furthermore, if it depends on the levels of humidity, the charge passed may be limited by the availability of $\mathrm{H}_{2} \mathrm{O}$.

The following reduction process could equally occur:

$\mathrm{H}_{2} \mathrm{O}+\mathrm{e}^{-} \rightarrow 1 / 2 \mathrm{H}_{2}+\mathrm{OH}^{-}$

The reduced form of the device has a number of defects which are termed oxygen vacancies, taken as dications. Thus, the material is nominally $\mathrm{p}$ doped in nature according to Strukov et al. [3] who state 'oxygen vacancies act a mobile +2 dopants which drift in the applied field'. However, in a separate paper, Ganduglia et al. [8] indicate that 'reduced 
$\mathrm{TiO}_{2}$ crystals exhibit $\mathrm{n}$ type doping'. Thus, there is a discrepancy in the literature regarding the charge-carrying species responsible for the conductivity in the reduced $\mathrm{TiO}_{2}$. It is reasonable to believe that the mobility of an electron (or hole) would be far greater than any ionic defect mobility.

According to Strunck et al. [6], the reduction of $\mathrm{Ti}^{4+}$ can occur with the oxidation of the $\mathrm{O}^{2-}$ to form oxygen.

$\mathrm{Ti}^{4+}-\mathrm{O}-\mathrm{Ti}^{4+} \rightarrow \mathrm{Ti}^{3+}-\square-\mathrm{Ti}^{3+}+1 / 2 \mathrm{O}_{2}$

However, if this is happening, then there is no overall passage of charge; this is merely a redox reaction where the $\mathrm{Ti}^{4+}$ is reduced and the oxygen is oxidised. Also, it would not explain how the conductivity of the material changes by a factor of 160-380 [3] since both the reagents and products are neutral.

Thus, it would be safe to assume that there is some transformation in the device that does produce defects that act as carriers. However, as mentioned, this reduction at one electrode must come with a concomitant oxidation at the other electrode. There have not been many publications that address this issue. A possible oxidation reaction may involve the presence of water, in the same way water is a component in reaction (1).

$\mathrm{H}_{2} \mathrm{O} \rightarrow 2 \mathrm{H}^{+}+1 / 2 \mathrm{O}_{2}+2 \mathrm{e}^{-}$

Oxidation of $\mathrm{O}^{2-}$ to form molecular oxygen has indeed been reported experimentally for $\mathrm{SrTiO}_{2}$ [9]. These results support the notion that the memristor behaves like an electrochemical cell, with oxidation on one side and reduction on the other.

When used as a photocatalyst, the charge carriers in $\mathrm{TiO}_{2}$ are clearly identified as holes or electrons. There are welldefined models involving the elevation of electrons from the conduction band to the valence band allowing simultaneous oxidation and reduction of different species at $\mathrm{TiO}_{2}$ nanoparticles' surfaces. This photocatalysis has widely been used to degrade organics in water [9-13]. The charge carriers in memristors have not been so easy to identify.

The aim of this work is to develop a simple electrochemical model based on a species in a thin layer, which can be oxidised at one electrode and reduced at the other. Diffusion and migration will be examined as the primary modes of transport to evaluate whether the current potential profiles are similar to those seen experimentally in classical memristors [2].

\section{Model}

The model consists of two electrodes; a working electrode (WE) at $x=0$ and a counter electrode (CE) at $x=d$. The material between these electrodes comprises a species $\mathrm{A}$, which is neutral. A voltage sweep is then applied to the WE to cause A to be oxidised. While this is happening, there will be an identical quantity of A reduced at the opposite (counter) electrode as follows:

$$
\begin{array}{ll}
\mathrm{A} \rightleftharpoons \mathrm{B}^{+}+\mathrm{e}^{-} & \text {at } x=0 \text { at the WE } \\
\mathrm{A}+\mathrm{e}^{-} \rightleftharpoons \mathrm{C}^{-} & \text {at } x=d \text { at the } \mathrm{CE}
\end{array}
$$

This mirrors the process happening at a $\mathrm{TiO}_{2}$-based memristor, where the $\mathrm{TiO}_{2}$ is reduced at the working electrode and oxidation occurs at the counter electrode. Here, there is no deliberately added electrolyte, which means that migration will occur.

Under this regime, the initial conditions are as follows:

$C_{\mathrm{A}}(x, 0)=C^{0}$

$C_{\mathrm{B}}(x, 0)=C_{\mathrm{C}}(x, 0)=0$

A potential sweep starts at a potential more negative than the $E^{\ominus}$ for the $\mathrm{A} / \mathrm{B}$ couple so that no electrochemical reaction happens. Next, the potential is swept at a certain scan rate past $E^{\ominus}$ for the couple and then is swept back.

At $x=0$, the following is true:

$E=E^{\ominus}+\frac{R T}{z F} \ln \left\{\frac{C_{\mathrm{B}}(0, t)}{C_{\mathrm{A}}(0, t)}\right\}$

Also at $x=0$

$\left.\frac{\mathrm{d} C_{\mathrm{A}}}{\mathrm{d} x}\right|_{x=0}=-\left.\frac{\mathrm{d} C_{\mathrm{B}}}{\mathrm{d} x}\right|_{x=0}$

At the counter electrode $x=1$, as $\mathrm{A}$ is being oxidised at the working electrode, it is also being reduced at the counter electrode.

$\left.\frac{\mathrm{d} C_{\mathrm{C}}}{\mathrm{d} x}\right|_{x=1}=\left.\frac{\mathrm{d} C_{\mathrm{A}}}{\mathrm{d} x}\right|_{x=0}$
$\left.\frac{\mathrm{d} C_{\mathrm{C}}}{\mathrm{d} x}\right|_{x=1}=-\left.\frac{\mathrm{d} C_{\mathrm{A}}}{\mathrm{d} x}\right|_{x=1}$

The equations to be solved are as follows where $i=\mathrm{A}, \mathrm{B}, \mathrm{C}$. $E$ is the potential applied to the WE, and the diffusion coefficients for $\mathrm{A}, \mathrm{B}$ and $\mathrm{C}$ are taken as $D$.

$\frac{\partial C_{\mathrm{i}}}{\partial t}=D\left[\frac{\partial^{2} C_{\mathrm{i}}}{\partial x^{2}}+\frac{z F}{R T}\left(\frac{\partial C_{\mathrm{i}}}{\partial x} \frac{\partial E}{\partial x}\right)\right]$

In addition, the following term is taken to be negligible, the so-called electroneutrality approximation.

$C_{\mathrm{i}}\left(\frac{\partial^{2} E}{\partial x^{2}}\right)=0$

Following the solution of these equations using the Crank Nicolson technique, currents were calculated [14-16]. 
The current resulting from diffusion is found as

$i=\left.z F A D \frac{\mathrm{d} C_{\mathrm{A}}}{\mathrm{d} x}\right|_{x=0}$

The current due to migration is given by the following expression evaluated at the working electrode surface:

$i=F A D\left(\frac{F}{R T} \frac{\partial E}{\partial x} \sum_{\mathrm{i}} z_{\mathrm{i}}^{2} C_{\mathrm{i}}\right)$

Equation (13), the Nernst Planck equation, has been considered by a number of groups, in electrolyte solutions, under conditions where the concentration of background electrolyte is quite small. In some cases, migration current is calculated $[17,18]$, using Eq. (16). A thin-layer dual-electrode configuration has previously been considered [18], where it was found that the migration current was hugely affected by the magnitude of the diffusion coefficient, $D$. Bieniasz $[19,20]$ solved the Nernst Planck equation for a rotating disk experiment. Also, a thin-layer cell was examined [21] and the current was calculated as the sum of Eqs. (15) and (16).

A second approach has also been taken [22-25]. This takes the view that Eq. (14) is not zero but is governed by the Poisson equation:

$\frac{\partial^{2} E}{\partial x^{2}}=-\frac{F}{\varepsilon \varepsilon_{0}} \sum_{i} z_{i} C_{\mathrm{i}}$

In this case, Eq. (17) is incorporated into Eq. (13) and solved. However, rather than calculating the mass transport controlled current and the migration current, the migration current was deemed to be zero as the zero-field approximation. The argument was that the double-layer thickness was insignificant in comparison with the diffusion layer thickness and

$\left.\frac{\mathrm{d} E}{\mathrm{~d} x}\right|_{x=0}=0$

More recently, the Nernst Planck-Poisson equation was used for nanometre-thick layers for a model ferrocene compound under steady-state conditions [26] and water electrolysis [27] in the absence of a deliberately added electrolyte. In each of these cases, migration and mass transport current were calculated. None of the systems mentioned above predict a behaviour which is characteristic of memristors [2,3], namely that the current on the reverse sweep of the voltammogram is greater than that on the forward sweep. All the modelling mentioned above was carried out for solution-based systems.

For the purpose of the simulation, dimensionless parameters are introduced where $h$ is the distance increment and $k$ is the time increment. $C^{0}$ is the initial concentration of $\mathrm{A}, D_{\mathrm{m}}$ is the dimensionless diffusion coefficient used in the simulation and $Z_{i}$ is the charge on the species.

$X=x / h$

$T=t / k$

$C_{\mathrm{A}}^{*}=C_{\mathrm{A}} / C^{0}$

$\phi=F E / R T$

$D_{\mathrm{m}}=D K /(h)^{2}$

Equations (7) and (8) become

$C_{\mathrm{A}}^{*}(x, 0)=1$

$C_{\mathrm{B}}^{*}(x, 0)=C_{\mathrm{C}}^{*}(x, 0)=0$

Equation (9) becomes

$\varnothing=\emptyset^{\ominus}+\ln \left\{\frac{C *_{\mathrm{B}}(0, t)}{C *_{\mathrm{A}}(0, t)}\right\}$

Also at $X=0$

$\left.\frac{\mathrm{d} C_{\mathrm{A}}^{*}}{\mathrm{~d} X}\right|_{X=0}=-\left.\frac{\mathrm{d} C_{\mathrm{B}}^{*}}{\mathrm{~d} X}\right|_{X=0}$

Equations (11) and (12) become

$\left.\frac{\mathrm{d} C_{\mathrm{C}}^{*}}{\mathrm{~d} X}\right|_{X=1}=\left.\frac{\mathrm{d} C_{\mathrm{A}}^{*}}{\mathrm{~d} X}\right|_{X=0}$

$\left.\frac{\mathrm{d} C_{\mathrm{C}}^{*}}{\mathrm{~d} X}\right|_{X=1}=-\left.\frac{\mathrm{d} C_{\mathrm{A}}^{*}}{\mathrm{~d} X}\right|_{X=1}$

Equation (13) becomes

$\frac{\partial C_{i}^{*}}{\partial T}=D_{\mathrm{m}}\left[\frac{\partial^{2} C_{i}^{*}}{\partial X^{2}}+\left(\frac{\partial C_{i}^{*}}{\partial X} \frac{\partial \varnothing}{\partial X}\right)\right]$

Equation (14) becomes

$\left(\frac{\partial^{2} \varnothing}{\partial X^{2}}\right)=0$

The currents (15) and (16) become

$i=\left.\frac{Z F A D_{\mathrm{m}} h C^{0}}{k} \frac{\mathrm{d} C_{\mathrm{A}}^{*}}{\mathrm{~d} X}\right|_{X=0}$

$i=\frac{z F A h D_{\mathrm{m}} C^{0}}{k}\left(\frac{\partial \varnothing}{\partial X} \sum_{\mathrm{i}} Z_{\mathrm{i}}^{2} C_{i}^{*}\right)$

The code was written in FORTRAN and the program run on a desktop PC. Typically, the number of distance increments was 200 and the number of time increments was 300 . Currents were calculated as diffusion current (Eq. 32) or migration 


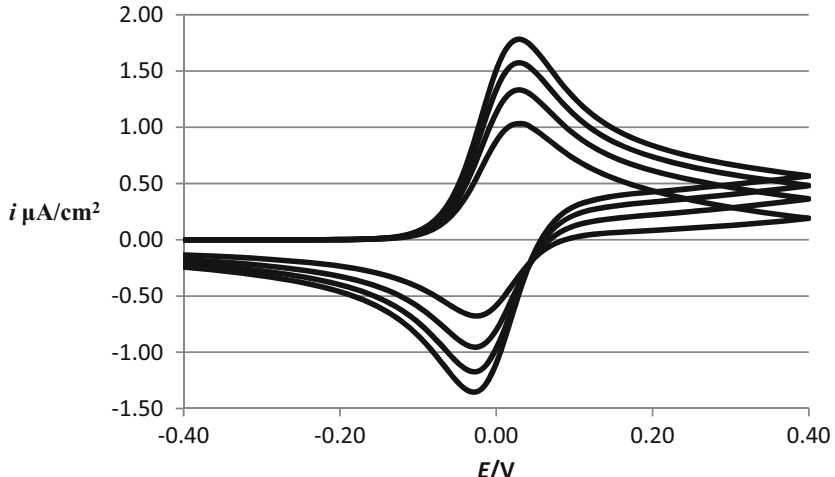

Fig. 1 Diffusion-controlled current calculated under the following conditions. Layer thickness, $d=2 \times 10^{-5} \mathrm{~cm}$, effective diffusion coefficient, $D=5 \times 10^{-11} \mathrm{~cm}^{2} / \mathrm{s}$, scan rates $0.3,0.5,0.7$ and $0.9 \mathrm{~V} / \mathrm{s}$ in order of increasing current. Bulk concentration of $1 \times 10^{-6}$ moles $\mathrm{cm}^{-3}$. $E^{\ominus}=0.0 \mathrm{~V}$

current (Eq. 33) separately. In this work, the electroneutrality approximation is invoked (Eq. 31) and the assumption is that the field at the working electrode surface is constant.

\section{Results and discussion}

Figure 1 shows the current/potential profile (cyclic voltammogram, termed $\mathrm{CV}$ ) for a situation where there is no migration. The charges on A, B and C are taken to be zero. The timescale is short enough that the diffusion layer of $\mathrm{A}$ is rather thick and so the CV looks like a bulk CV. In fact, if the peak current was plotted against the square root of the sweep rate, then a linear relationship results with a correlation coefficient of one and a zero intercept [28]. This is a confirmation that diffusion is the rate-determining step and that the kinetics are fast. The diffusion coefficient, $D\left(5 \times 10^{-11} \mathrm{~cm}^{2} / \mathrm{s}\right)$, is typical of solid-state devices [16] and also for polymer-confined redox species [29], and the layer thickness is $200 \mathrm{~nm}$.

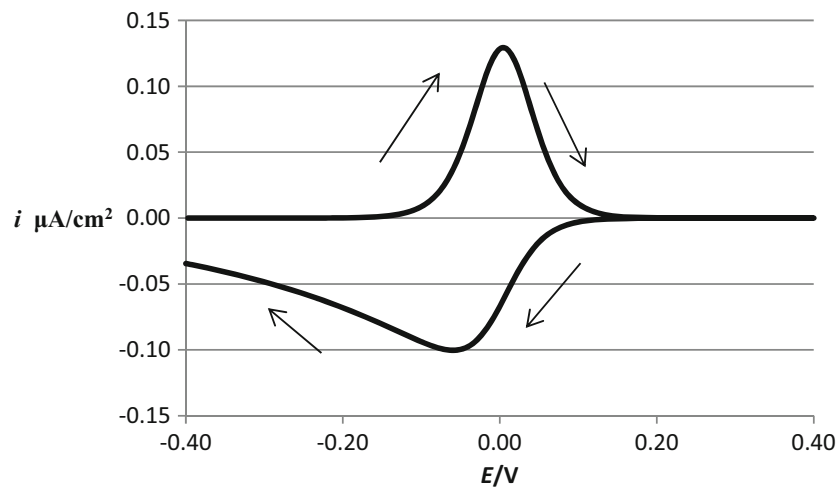

Fig. 2 Diffusion-controlled current calculated under the following conditions. Layer thickness, $d=2 \times 10^{-5} \mathrm{~cm}$, effective diffusion coefficient, $D=5 \times 10^{-11} \mathrm{~cm}^{2} / \mathrm{s}$, scan rate is $0.01 \mathrm{~V} / \mathrm{s}$. Bulk concentration of $\mathrm{A}$ is $1 \times 10^{-6}$ moles $\mathrm{cm}^{-3}$. $E^{\ominus}=0.0 \mathrm{~V}$

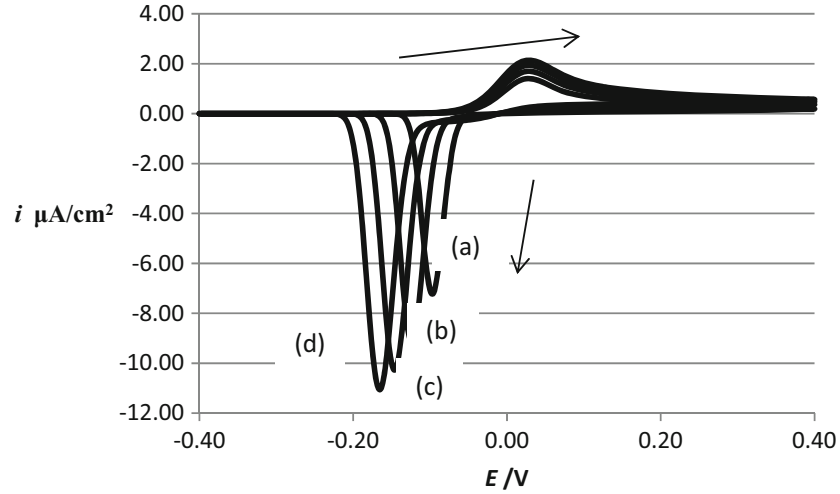

Fig. 3 Diffusion-controlled current calculated under the following conditions. Layer thickness, $d=2 \times 10^{-5} \mathrm{~cm}$, effective diffusion coefficient, $D=5 \times 10^{-11} \mathrm{~cm}^{2} / \mathrm{s}$, scan rates $(a) 0.3,(b) 0.5,(c) 0.7$ and (d) $0.9 \mathrm{~V} / \mathrm{s}$ in order of increasing current. Bulk concentration of $\mathrm{A}$ is $1 \times 10^{-6}$ moles $\mathrm{cm}^{-3} . E^{\ominus}=0.0 \mathrm{~V} . Z_{\mathrm{A}}=0, Z_{\mathrm{B}}=+1, Z_{\mathrm{C}}=-1$. NOTE: "The arrows indicate the direction in which the potential is swept from $-0.4 \mathrm{~V}$ to $+0.4 \mathrm{~V}$ "

If the layer thickness was decreased or the timescale increased, then the CV would appear to be closer to a thinlayer $\mathrm{CV}$ with symmetric forward and reverse peaks. Figure 2 shows this situation at a lower scan rate than that in Fig. 1. It does have the appearance of an ideal thin-layer $\mathrm{CV}$ as the species A is completely consumed on the forward sweep. However, A is also being consumed at the counter electrode, which introduces a distortion on the reverse sweep as can be seen on the negative-going sweep in Fig. 2.

Migration is introduced by changing the charges for $Z_{\mathrm{A}}, Z_{\mathrm{B}}$ and $Z_{\mathrm{C}}$ to be $0,+1$ and -1 , respectively. This affects the diffusion component of the current as seen in Fig. 3, which occurs under the same conditions as in Fig. 1.

Figure 3 shows the diffusion-limited current found from Eq. (32), and it can be seen that the current increases with scan rate as in Fig. 1. However, because of the charges on B and $\mathrm{C}$, following their formation from $\mathrm{A}, \mathrm{B}^{+}$migrates to the counter electrode and $\mathrm{C}^{-}$migrates to the working electrode.

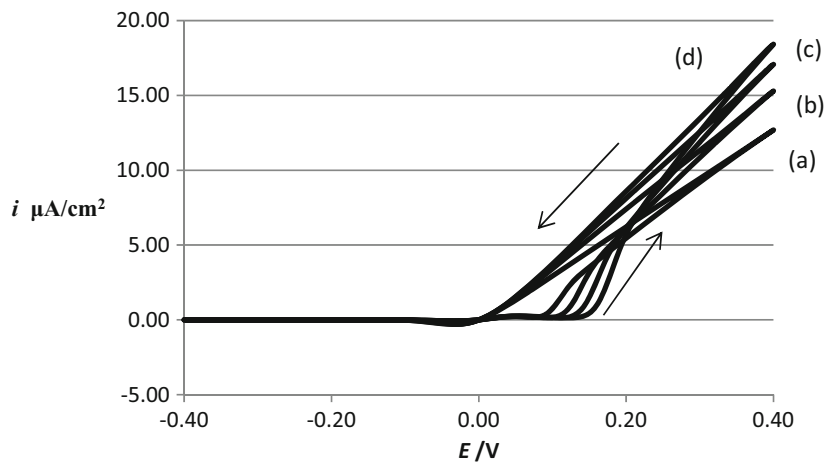

Fig. 4 Migration current calculated under the following conditions. Layer thickness, $d=2 \times 10^{-5} \mathrm{~cm}$, effective diffusion coefficient, $D=5 \times 10^{-11} \mathrm{~cm}^{2} /$ $\mathrm{s}$, scan rates $(a) 0.3,(b) 0.5,(c) 0.07$ and $(d) 0.9 \mathrm{~V} / \mathrm{s}$. The currents increase with scan rate. Bulk concentration of $\mathrm{A}$ is $1 \times 10^{-6}$ moles $\mathrm{cm}^{-3} \cdot E^{\ominus}=0.0 \mathrm{~V}$. $Z_{\mathrm{A}}=0, Z_{\mathrm{B}}=+1, Z_{\mathrm{C}}=-1$. NOTE: "The arrows indicate the direction in which the potential is swept from $-0.4 \mathrm{~V}$ to $+0.4 \mathrm{~V}$ " 


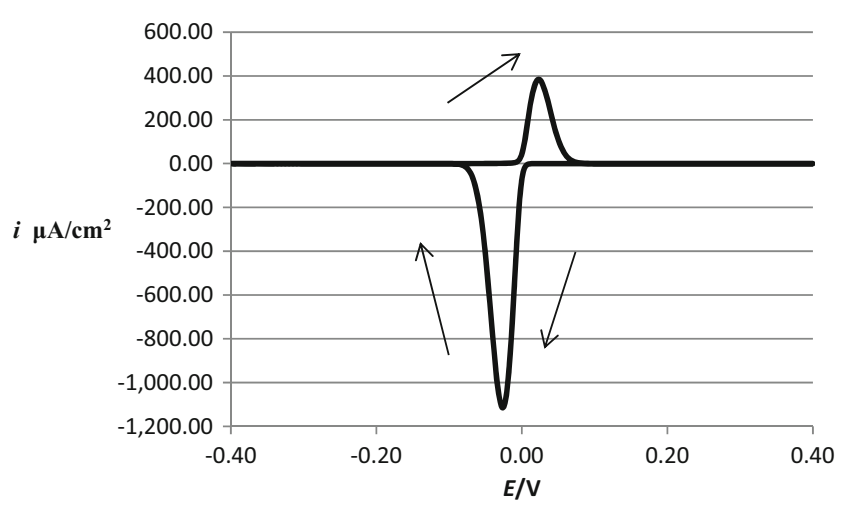

Fig 5 Diffusion-controlled current calculated under the following conditions. Layer thickness, $d=2 \times 10^{-5} \mathrm{~cm}$, effective diffusion coefficient, $D=5 \times 10^{-8} \mathrm{~cm}^{2} / \mathrm{s}$, scan rates $0.3,0.5,0.7$ and $0.9 \mathrm{~V} / \mathrm{s}$ in order of increasing current. Bulk concentration of $\mathrm{A}$ is $1 \times 10^{-6}$ moles $\mathrm{cm}^{-3}$. $E^{\ominus}=0.0$ V. $Z_{\mathrm{A}}=0, Z_{\mathrm{B}}=+1, Z_{\mathrm{C}}=-1$. NOTE: "The arrows indicate the direction in which the potential is swept from $-0.4 \mathrm{~V}$ to $+0.4 \mathrm{~V}$ "

Consequently, on the reverse sweep, it takes time for them to diffuse back to their respective electrodes for reaction. Thus, at faster scan rates, the potential at which $\mathrm{B}^{+}$is reduced is more negative as it cannot reach the working electrode in sufficient time. It can be seen in Fig. 3 that the current profile on the forward sweep is that of a bulk diffusion process; however, migration influences the mass transport of $\mathrm{B}$ yielding a peak typical of a thin layer. Once the potential is negative, B migrates to the working electrode.

Figure 4 shows the migration current under these conditions. One notable characteristic is that the reverse current is greater than the forward current and that the current has a resistive behaviour. On the reverse sweep, once the potential is swept past $0 \mathrm{~V}$, the migration current becomes very small as the concentration of $\mathrm{C}^{+}$and $\mathrm{B}^{-}$decreases rapidly. It can be seen that the migration current dominates the response as it is a factor of ten greater than the diffusion current.

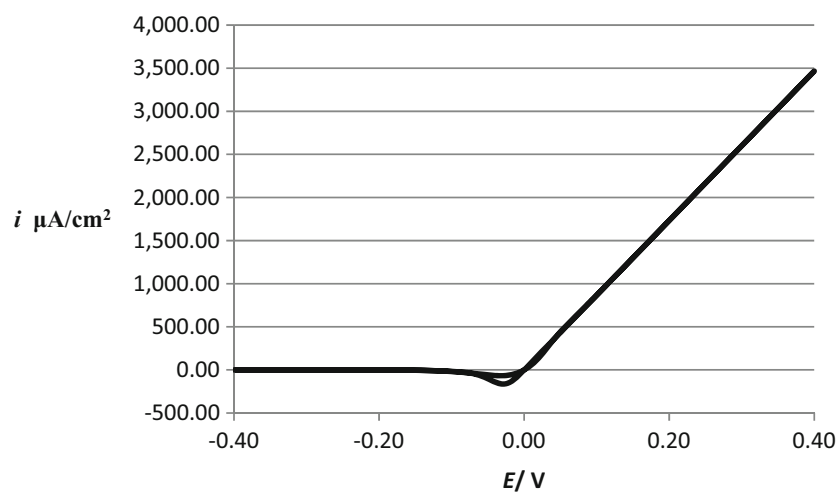

Fig 6 Migration current calculated under the following conditions. Layer thickness, $d=2 \times 10^{-5} \mathrm{~cm}$, effective diffusion coefficient, $D=5 \times 10^{-8} \mathrm{~cm}^{2} /$ $\mathrm{s}$, scan rates $0.3,0.5,0.7$ and $0.9 \mathrm{~V} / \mathrm{s}$. The currents increase with scan rate. Bulk concentration of $\mathrm{A}$ is $1 \times 10^{-6}$ moles $\mathrm{cm}^{-3} \cdot E^{\ominus}=0.0 \mathrm{~V} \cdot Z_{\mathrm{A}}=0, Z_{\mathrm{B}}=+$ $1, Z_{\mathrm{C}}=-1$
Figure 5 is an overlay of the diffusion current at different scan rates under conditions when the diffusion coefficient, $D$, is much larger. It can be seen that there is a greater effect due to the presence of the potential field, in that the current does not change at all with scan rate. It has been cited elsewhere that the magnitude of the diffusion coefficient influences migration to a large extent. The forward current is affected, even though A is neutral. In Fig. 6, once again, there are a number of overlaid voltammograms with no hysteresis, on account of the larger diffusion coefficient. There is also a coincidence in the peak potential for the reduction of $\mathrm{B}$ in the diffusion-limited current (Fig. 5) and the negative peak of the migration current in Fig. 6 that falls to zero since the remaining $\mathrm{B}$ and $\mathrm{C}$ are converted back to A. The currents in Figs. 5 and 6 are much greater than those in Figs. 3 and 4 due to the greater magnitude of the diffusion coefficient, $D$.

\section{Conclusion}

With the caveat of the assumptions made in this model, namely that the electroneutrality approximation applies and that the field at the working electrode surface is constant, the current voltage behaviour of the migration component of the current mirrors that often exhibited by memristors. There is a hysteresis under conditions of low diffusion coefficient, with a resistive-like behaviour. Also, there is zero current when the potential is zero, which is an attribute of memristors $[2,3]$. From the CVs in Figs. 4 and 6, it can be seen that the model is a phenomenological alternative to others used to explain the behaviour of memristors.

\section{References}

1. Gale E (2014) Semicond Sci Technol 29:104004-104014

2. Chua L (2011) Appl Phys A Mater Sci Process 102:765-783

3. Strukov DB, Snider GS, Stewart DR, Williams RS (2009) Nature 453:80-83, Correction Nature (2009) 4591154

4. Shoute LCT, Pekas N, Wu Y, McCreery RL (2011) Appl Phys A Mater Sci Process 102:841-849

5. Wu J, McCreery RL (2009) J Electrochem Soc 156:P29-P37

6. Strunk J, Vining WC, Bell AT (2010) J Phys Chem C 114:1693716945

7. Zhao J, Xing W, Li Y, Lu K (2015) Materials Letters 145:332-335

8. Ganduglia-Pirovano MV, Hofmann A, Sauer J (2007) Surf Sci Rep 62:219-270

9. Szot K, Speier W, Bihlmayer G, Waser R (2006) Nat Mater 5:312320

10. Malato S, Blanco J, Vidal A, Richter C (2002) Appl Catal B 37:115

11. Alfano OM, Bahnemann D, Cassano AE, Dillert R, Goslich R (2000) Catal Today 58:199-230

12. Bahnemann D (2004) Sol Energy 77:445-459 
13. Devipriya S, Yesodharan S (2005) Sol Energy Mater Sol Cells 86: 309-348

14. Britz D (1981) Digital simulation in electrochemistry. Springer Verlag, Berlin

15. Feldberg SW (1969) In: Bard AJ (ed) In electroanalytical chemistry, vol 3. Marcel Dekker, New York

16. Cassidy J (1996) In: Lyons MEG (ed) Chapter 6 in 'Electroactive polymer electrochemistry part II, fundamentals and applications'. Plenum Press, New York

17. Palys MJ, Stojek Z (2002) J Electroanal Chem 534:65-73

18. Hyk W, Stojek Z (2013) Electrochem Commun 34:192-195

19. Bieniasz LK (2004) J Electroanal Chem 565:251-271

20. Stevens NPC, Bond AM (2002) J Electroanal Chem 538-539:2533

21. Myland JC, Oldham KB (2004) J Electroanal Chem 568:101-114
22. Belding SR, Compton RG (2012) J Electroanal Chem 683: $1-13$

23. Limon-Petersen JG, Dickinson EJF, Belding SR, Rees NV, Compton RG (2010) J Electroanal Chem 650:135-142

24. Barnes EO, Wang Y, Limon-Petersen JG, Belding SR, Compton RG (2011) J Electroanal Chem 659:25-35

25. Barnes EO, Belding SR, Compton RG (2011) J Electroanal Chem 660:185-194

26. van Soestbergen M (2012) Electrochem Commun 20:105-108

27. Aoki KJ, Li C, Nishiumi T, Chen J (2013) J Electroanal Chem 695: 24-29

28. Oldham KB, Myland JC, Bond AM (2012) Electrochemical science and technology, fundamentals and applications. Wiley, Chichester

29. Cassidy JF, Breen W, McGee A, Vos JG, Lyons MEG (1992) Electroanalysis 4:751-756 